NOTES

\title{
Estimation of Hard Segment Content in Polyurethane from Solvent Absorption
}

\author{
K. SReEnivasan \\ Biomedical Technology Wing, Sree Chitra Tirunal Institute \\ for Medical Sciences and Technology, Poojapura, \\ Trimvandrum-695012, India
}

(Received October 12, 1989)

KEY WORDS Polyurethane / Hard Segment / Absorption /

Interesting properties of segmented polyurethanes have been traced to the realization of phase separated microstructure. The typical phase separated structure in this class of materials had been probed extensively using $\mathrm{X}$-ray scattering and electron microscopic studies. ${ }^{1-3}$ However, it has been pointed out that the detailed domain structure and its unification are not completely possible from any of the above mentioned techniques. ${ }^{4}$ Diffusion of small molecules on the other hand is shown to provide insight into the intricacy of the microstructure since these types of diffusants scales with the domain sizes in polyurethanes. To date most of the diffusion studies in polyurethanes are aimed either to understand the overall morphology of the polymer or to elucidate the diffusion mechanism in these polymers. ${ }^{5-7}$ Interestingly diffusional aspects could be used as a tool to estimate some of the basic parameters of the polymer, e.g., hard/soft segment content. Our interest here is to show a simple correlation between extent of absorption of a diffusant and hard segment content.

\section{EXPERIMENTAL}

The polyurethane used in this study was prepared using methylene bis( $p$-cyclohexyl isocyanate) $\left(\mathrm{H}_{12} \mathrm{MDI}\right)$ (Bayer), polytetramethylene glycol 1990 (PTMEG 1990) (QO Chemicals, U.S.A.), and 1,4-butane diol (BD) (Merck).

\section{Polymer Synthesis}

To slightly excess $\mathrm{H}_{12} \mathrm{MDI}(1.05 \mathrm{~mol})$ taken in a resin kettle, PTMEG $1990(0: 75 \mathrm{~mol})$ was added slowly under stirring followed by the addition of $20 \mathrm{ml}$ dimethyl acetamide (DMAC). $0.2 \%$ dibutyltin dilaurate (catalyst) was added and the temperature raised to $60^{\circ} \mathrm{C}$. The reaction was carried out under a nitrogen atmosphere and continued for about $3 \mathrm{~h}$. BD $(0.25 \mathrm{~mol})$ was added after cooling the reaction mixture to $40^{\circ} \mathrm{C}$. It was stirred for $1 \mathrm{~h}$ raising the temperature to $60^{\circ} \mathrm{C}$. The contents were cured at $65^{\circ} \mathrm{C}$ for nearly $48 \mathrm{~h}$ after transferring to a glassplate. Then the polymer was dissolved in DMAC, cast into a film and dried at $60^{\circ} \mathrm{C}$ in vacuum. The polymer film was then extracted with water, ethyl alcohol and finaly hexane to remove residual solvent, unreacted ingredients and impurities. The vacuum dried films were then used for further study. 


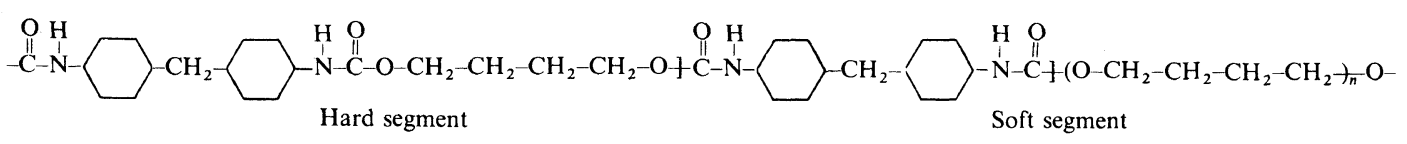

Table I. Relevant parameters of the polymers

\begin{tabular}{cccrrr}
\hline Polymer & $\begin{array}{c}\text { Reactant ratios } \\
\left(\mathrm{H}_{12} \mathrm{MDI} / \mathrm{BD} / \mathrm{PTMEG}\right)\end{array}$ & $\begin{array}{c}\text { Fraction of hard } \\
\text { segment }\end{array}$ & $\boldsymbol{M}_{w}$ & $M_{n}$ & $D\left(M_{w}\right)\left(M_{n}\right)$ \\
\hline $\mathrm{P}_{1}$ & $1.05 / 0.25 / 0.75$ & 0.17 & 144000 & 67000 & 2.14 \\
$\mathrm{P}_{2}$ & $1.05 / 0.47 / 0.53$ & 0.23 & 210000 & 105000 & 2.01 \\
$\mathrm{P}_{3}$ & $1.05 / 0.66 / 0.34$ & 0.33 & 232000 & 109000 & 2.12 \\
$\mathrm{P}_{4}$ & $1.05 / 0.8 / 0.2$ & 0.47 & 163000 & 87000 & 1.87 \\
$\mathrm{P}_{5}$ & $1.05 / 0.91 / 0.09$ & 0.66 & 183000 & 84700 & 2.16 \\
$\mathrm{P}_{6}$ & $1.05 / 1.0 / 0$ & 1.00 & 83000 & 37200 & 2.23 \\
\hline
\end{tabular}

The fraction of hard segment content was determined from [Weight of isocyanate + Weight of chain extender(BD) $] \div[$ Total weight (isocyanate $+\mathrm{BD}+$ polyol)]. By changing the molar ratios of $\mathrm{H}_{12} \mathrm{MDI} / \mathrm{BD} / \mathrm{PTMEG}$, polymers having hard and soft segment contents were synthesized. Molecular weight parameters were estimated by the gel permeation chromatographic method. Molar ratios together with other relevant parameters are summarized in Table I.

Toluene was used as a diffusant. Cleaned polymer strips of different hard/soft segment contents and of thickness of $0.5 \mathrm{~mm}$ and $2 \times 2$ sq. $\mathrm{cm}$ were used for the absorption studies. The polymer strips were immersed in Toluene at $25 \pm 0.1^{\circ} \mathrm{C}$. The weight of the strips was monitored at regular time intervals. After some time, the weight became constant and the extent of absorption was estimated from $\left.\left\{W-W_{0}\right)\right\}$ $\left.W_{0}\right\} \times 100$, where $W$ is the final weight and $W_{0}$ is the initial weight and this value was taken as the percentage equilibrium absorption.

\section{RESULTS AND DISCUSSION}

Table II summarizes the \% equilibrium absorption by the polymers having hard segment content. The extent of absorption sharply drops with the hard segment content.
Table II. Extent of absorption of the diffusant with hard segment content

\begin{tabular}{ccc}
\hline Polymer & $\begin{array}{c}\text { Fraction of hard } \\
\text { segment content } \\
(X)\end{array}$ & $\begin{array}{c}\text { Equilibrium } \\
\text { absorption } \\
(S) / \%\end{array}$ \\
\hline $\mathrm{P}_{1}$ & 0.17 & $307 \pm 5$ \\
$\mathrm{P}_{2}$ & 0.23 & $204 \pm 2$ \\
$\mathrm{P}_{3}$ & 0.33 & $117 \pm 3$ \\
$\mathrm{P}_{4}$ & 0.47 & $61 \pm 1$ \\
$\mathrm{P}_{5}$ & 0.66 & $25 \pm 0.5$ \\
$\mathrm{P}_{6}$ & 1.00 & 0 \\
\hline
\end{tabular}

$P_{6}(100 \%$ hard segment material) is totally impermeable to the diffusant. The lack of segment mobility in hard domain (glass transition temperature of hard segment is far above room temperature) at the experimental temperature, is the factor for the impermeability. The soft segment on the other hand possess substantial chain mobility at $25^{\circ} \mathrm{C}$ facilitating the diffusion.

Figure 1 graphically illustrates the equilibrium absorption versus fraction of hard segment content. The curves sharply drop as the hard segment increases. The hard domains acting as physical crosslinks, restrict the soft segment mobility. This in fact, reduces the probability for creating an adequate volume for diffusion. Further, the extent of phase mixing has been shown to be more with increase 


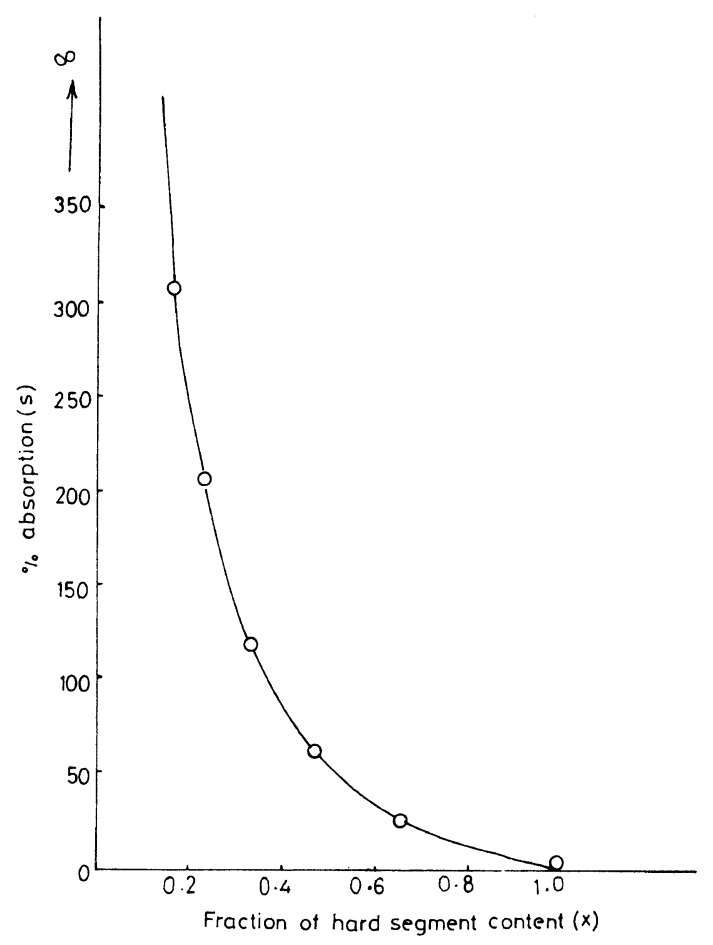

Figure 1. A typical plot of \% equilibrium absorption versus fraction of hard segment content.

of hard segment. ${ }^{8}$ More phase mixing could reduce further the soft segment mobility which is unfavourable to diffusion.

The \% absorption reduces to zero when the hard segment becomes $1 \quad(100 \%$ hard segment). Interestingly, the curve rapidly rises to infinity as the hard segment $\rightarrow 0$ $(100 \%$ soft segment) (see Figure 1). The nature of the curve can fit into an empirical equation of the form $S=A\left\{(1-X) /\left(e^{X}-1\right)\right\}$ where $S=\%$ equilibrium absorption of diffusant, $A$, an emp irical constant and $X$ is the fraction of hard segment. The equation, interestingly, provides both limits $S=0$ when $X=1$ and $S=\infty$. When $X=0$.

The equation is simple and involved only two parameters. The extent of absorption can casily be determined. There is thus another way to estimate the hard segment content in polyurethanes.

\section{REFERENCES}

1. J. Blackwell and K. H. Gardner, Polymer, 20, 13 (1979).

2. R. R. Lagassee, J. Polym. Sci., 21, 2489 (1977).

3. C. H. Y. Chem. Tsai, E. L. Thomas, W. J. Macknight, and M. S. Schneider, Polymer, 27, 659 (1986).

4. M. Serrano, W. J. Macknight, E. L. Thomas, and J. M. Ottino, Polymer, 28, 1674 (1987).

5. K. D. Ziegel, J. Macromoli Sci. Phys., B5(1), 11 (1971).

6. J. S. Mcbride, T. A. Massaro, and S. L. Cooper, J. Polym. Sci., 23, 201 (1979).

7. R. Goydan, N. S. Schneider, and J. Meldon, $J$. Polym. Mater. Sci. Eng., 49, 249 (1983).

8. J. W. C. Van Bogart, A. Lilaonitkul, L. E. Lerner, and S. L. Cooper, J. Macromol. Sci. Phys., B17(2), 267 (1980). 